\title{
Stage IIIC Hepatocellular Carcinoma AJCC v7
}

National Cancer Institute

\section{Source}

National Cancer Institute. Stage IIIC Hepatocellular Carcinoma A/CC v7. NCI Thesaurus. Code C88044.

Stage IIIC includes: T4, N0, M0. T4: Tumors(s) with direct invasion of adjacent organs other than the gallbladder or with perforation of visceral peritoneum. NO: No regional lymph node metastasis. M0: No distant metastasis. (AJCC 7th ed.) 